\title{
Radar GPR accuracy in detection and distinguishing buried targets different in physical properties
}

\author{
Fouad Lahlal $^{1}$, Ahmed Faize ${ }^{1}$, Mohamed Atounti ${ }^{2}$, Gamil Alsharahi ${ }^{1}$ \\ ${ }^{1}$ Department of Physics, Faculty of Polydisciplinary, Mohammed First University, Morocco, \\ f.lahlal@ump.ac.ma, ahmedfaize6@hotmail.com, alsharahigamil@gmail.com \\ ${ }^{2}$ Laboratory of Applied Mathematics and Information Systems, Faculty of Polydisciplinary, Mohammed First \\ University, Morocco.m.atounti@ump.ac.ma
}

\begin{abstract}
This article is intended to study the resolution of ground penetration radars (GPR). Thus, the characteristics of the pulses emitted by the GPR radar antennas determine the quality of the target reflections. In order to complete a GPR survey, it is important to know as much as possible the transmission characteristics of these antennas. This information is very important for selecting the appropriate antennas and setting configuration parameters for a specific survey. It is with this in mind that this article deals with the development of a simulation set, based on the finite difference method in the temporal domain (FDTD), on the ability to detect and distinguish objects in different situations. In one particular case, the results of these simulations of the $400 \mathrm{MHz}$ antenna provide an estimate of the resolution of the antennas being tested. The conclusions reached are the first step in establishing the actual limits of the detection capacity of these antennas.
\end{abstract}

Key words: Ground Penetrating Radar (GPR), antenna resolution, Simulation; physical properties, detecting, distinguishing.

\section{INTRODUCTION}

Ground penetration radar (GPR) plays a growing role in nondestructive exploration, imaging of the polled media is based on the emission of electromagnetic waves (EM) in the hyperfrequency range (about 100 to $3000 \mathrm{MHz}$ ) that spread through the various layers of the prospected (heterogeneous) media, through a resistive dipole that acts as a resistive dipole transmitter, and to record with another dipole at reception a portion of their energy reflected by any interface with dielectric contrast [1],[2].This technique has great potential and is commonly used for the study of subsurface in civil engineering, geological and geotechnical studies, mapping and discovery of public services, which has led to an increasing demand for techniques that can represent the basement at a higher resolution than possible before [3],[4] [5], [6].
Numerical modeling and simulation of widely used GPR systems and have been recognized as the best way to achieve our results. A variety of differential equations and integral equations based on numerical modeling techniques have been developed for this purpose [7], [8]. The spatial resolution depends on the characteristics of the radar and survey signal, the (EM) electromagnetic properties of the environment studied and the distance from the antenna to the target. The frequencies, the number of scans on the target, and the spatial configuration of the antenna beam are the characteristics that define the radar signal and the investigation [9], [10]. The resolution of the characteristics of the subsoil is partly affected by the wavelength antenna which is directly linked to the higher frequency for a frequency of GPR providing a higher resolution than the lower radar frequency [11].

In this article, we studied the horizontal and vertical resolution of the two objects using the simulation on Reflexw. The distance between horizontally and vertically placed objects has been calculated. For the horizontal position, the GPR uses the wavelength and for the vertical, it uses the frequency pulse and the duration. The simulation was compared with data from experimental work [12] and the results showed good performance.

In particular, this work concerns the development of a simulation set to analyze the resolution capacity of the three bowtie antennas at the frequency of $400 \mathrm{MHz}$, which makes the simulation at their real resolution capacity and the comparison with the theory [13]. The presentation of this document focuses on the methodology proposed to carry out the resolution of the antenna [14].

\section{MATERIAL AND THEORY}

\subsection{Methodology}

In this work, we distinguish between buried objects of the same type and geometrics shape with simulation by Reflexw software. who used the same objects: rectangular objects and circular bar buried in a medium of air. In the first stage, we detect each body separately, conductor, dielectric and different shapes, then we detect two bodies buried together 
horizontally and vertically and in the other three bodies buried together horizontally and vertically and this process is done to detect previous objects when they are of the same type. In the second stage, we detect the different objects in the physical properties (table1), buried horizontally and vertically [15], [16].

Table 1: Physical properties of the materials

\begin{tabular}{|c|c|c|c|}
\hline Material & $\begin{array}{c}\text { Relative } \\
\text { permittivity } \\
(\mathbf{F} / \mathbf{m})\end{array}$ & $\begin{array}{c}\text { Conductivity } \\
(\mathbf{S} / \mathbf{m})\end{array}$ & $\begin{array}{c}\text { Velocity } \\
(\mathbf{m} / \mathbf{n s})\end{array}$ \\
\hline Wood & 3 & 0.003 & 0.17 \\
\hline Iron & 1.45 & $9.99 \times 106$ & 0.24 \\
\hline Air & 1 & 0 & 0.3 \\
\hline Dry sand & 6 & 0.0001 & 0.12 \\
\hline Soil & 9 & 0.001 & 0.1 \\
\hline
\end{tabular}

\subsection{Numerical modeling of Reflexw software}

Reflexw is one of the software packages for geophysical processing and interpretation. This software is based on direct modeling to simulate the propagation of EM waves, based on the finite-difference in the time-domain (FDTD) algorithm. This FDTD method is based on the local resolution of the two Maxwell-Faraday and MaxwellAmpère equations, the internal structures of the geological models studied can be discredited spatially and temporally using a mesh-based on The Yee Schema, in order to evolve the electric and magnetic fields, illustrated by the Maxwell equations (1) and (2), describing the propagation of the EM wave in the simulated medium [17].

$$
\begin{aligned}
& H_{z_{i+1 / 2, j+1 / 2}}^{n+1 / 2}=H_{z_{i+1 / 2, j+1 / 2}}^{n-1 / 2}+\frac{\Delta t}{\mu \Delta y}\left[E_{x_{i+1 / 2, j+1}}^{n}-E_{x_{i+1 / 2, j}}^{n}\right] \\
&-\frac{\Delta t}{\mu \Delta x}\left[E_{y_{i+1, j+1 / 2}}^{n}-E_{x_{i, j+1 / 2}}^{n}\right] \\
& E_{z_{i, j}}^{n+1}=E_{z_{i, j}}^{n}+\frac{\Delta t}{\varepsilon \Delta y}\left[H_{x_{i, j+1 / 2}}^{n+1 / 2}-H_{x_{i, j-1 / 2}}^{n+1 / 2}\right] \\
& \quad-\frac{\Delta t}{\varepsilon \Delta x}\left[H_{y_{i+1 / 2, j}}^{n+1 / 2}-H_{y_{i-1 / 2}, j}^{n+1 / 2}\right]
\end{aligned}
$$

\subsection{Investigative problem}

GPR information can be affected during transmission and reflection of pulses by the physical properties $(\sigma$, $\varepsilon a n d \mu)$ of the surveyed media, the speed of propagation and the depth of the buried objects, which directly influences the quality of the amplitude of the EM waves reflected, transmitted andlor refracted between the transmitter and the receiver, these parameters are very important to determine how targets can be accurately located, and thus to deduce the nature and distribution It is therefore essential to define a protocol of measures in advance. This will depend on the following considerations:

\section{A. GPR Equation}

The GPR equation characterizes the radar system performance relative to technical parameters of the transmitter, receiver, antenna characteristics, and properties of media and target objects. The radar equation can be defined as [18],[19],[20].

$$
Q=\frac{\xi_{T} \xi_{R} G_{T} G_{R} g S e^{-4 \alpha L}}{64 \pi^{3} f^{2} L^{4}}
$$

Where $Q$ is system performance (ratio of the emitted signal amplitude to the minimum receiver sensitivity);

$\xi_{T}$ is transmitter antenna efficiency;

$\xi_{R}$ is receiver antenna efficiency;

$G_{T}$ is transmitter antenna gain;

$G_{R}$ is receiver antenna gain;

$L$ is distance to the target;

$A$ is attenuation coefficient;

$f$ is frequency;

$g$ is backscatter gain of target;

Sis the target area.

The technical parameters of the GPR radar are the easy-tocontrol factors that influence the performance of the system and can be measured accurately enough, while the soil properties and targets are the most difficult to predict, and obtaining a reliable estimate of the extent of the radar signals requires site testing.

\section{B. Space resolution}

The resolution of GPR systems is a very important parameter to determine how targets can be accurately located, and thus to deduce the nature and spatial distribution of these materials. Vertical resolution (depth or longitudinal) noted $\left(\Delta_{V}\right)$ and horizontal resolution (transverse range) noted $\left(\Delta_{V}\right)$ (Figure 1), sometimes necessary to conduct operations of GPR surveys [21].

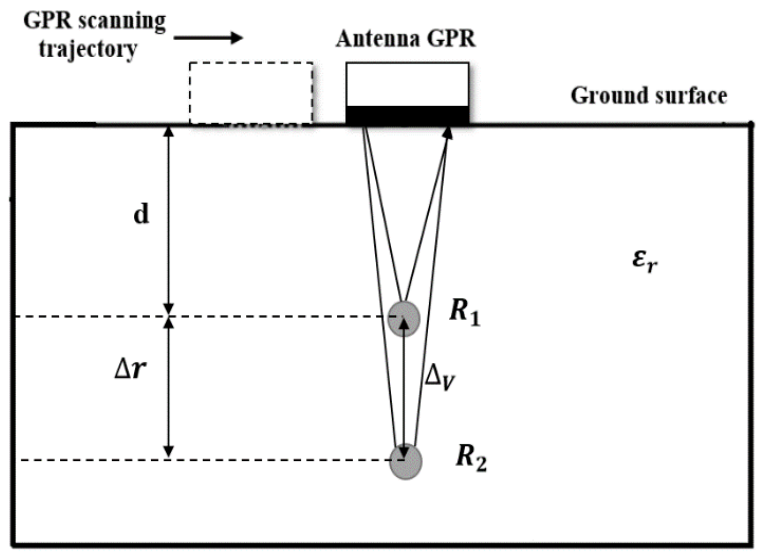

Figure 1: Reflections from two targets with vertical separation $\Delta r$.

Thus, the vertical resolution depends on the duration $\Delta \mathrm{t}$ of the radar pulse, which is linked to the center frequency of the antenna as follows:

$$
\Delta_{V} \approx \frac{\tau_{p} v}{4}=\frac{\tau_{p} c}{4 \sqrt{\varepsilon_{r}}}
$$


Where $\tau_{p}$ is the effective duration of the radar pulse obtained from the width of the signal envelope at its $-3 \mathrm{~dB}$ level, given by:

$$
\tau_{p}=2 \Delta t=2\left(t_{2}-t_{1}\right)=\frac{4 \Delta_{r}}{v}
$$

Where $\Delta t$ is the duration of the radar pulse between two targets separated vertically by a distance equal to $\Delta_{r}$ in $(n s)$, $v$ is the velocity of the wave propagation in the medium in $(n s / m)$.

For most natural materials, this approach does not take into account the dispersion effect due to the attenuation of electromagnetic waves that increases with frequency. This low-pass filter effect in propagating materials increases the pulse duration and therefore increases the resolution. Earth materials with high water content tend to have higher attenuation properties, but this feature is offset by reduced pulse length due to slower wave velocity in wetter materials [22].

Horizontal resolution consists of lateral separation of objects from the basement, which is the minimum distance that should exist between two reflectors located next to each other at the same depth so that the radar detects them as distinct events(Figure 2)[23].This resolution is related to the width of the wave beam emitted by the antenna. A narrower beam will of course give a better horizontal resolution. The beam can be considered as the energy cone that will intersect the reflecting surface. So it's going to touch an area that's called the antenna footprint. This area is visible in Figure 3. The influence zone is defined as the zone that can contain a second target that cannot be resolved uniquely.

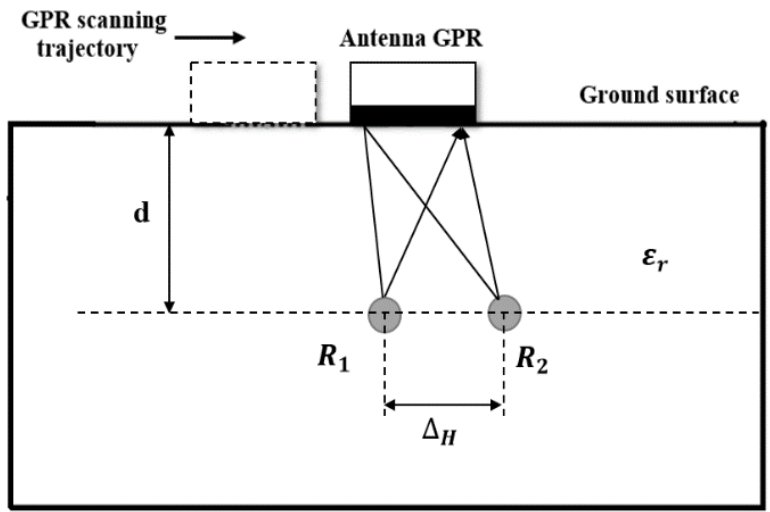

Figure 2: Schematic representation of the antenna footprint, which is used to define the horizontal resolution.

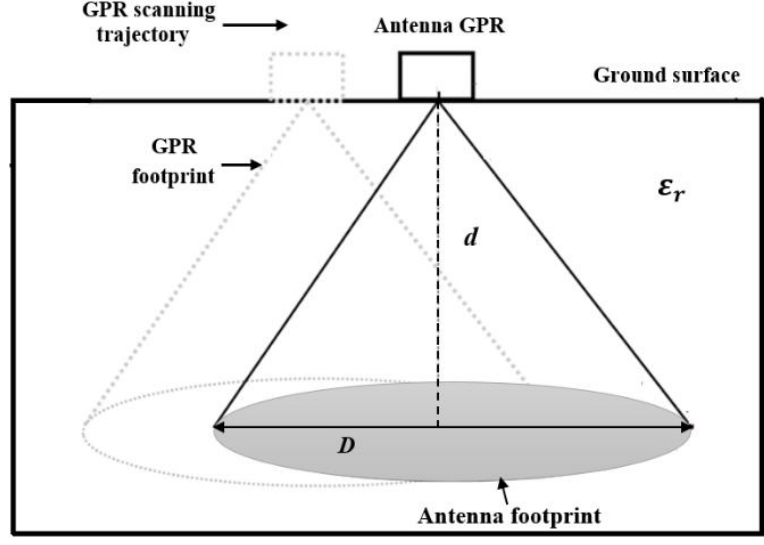

Figure 3 :Reflections from two targets with horizontal separation $\Delta_{H}$.

So that the horizontal resolution can be identified with the size of the fingerprint. A common approximation identifies the fingerprint with the diameter (D) of the first Fresnel area given by equation (6):[24].

$$
\Delta_{\mathrm{H}}=\mathrm{D}=\sqrt{\frac{\lambda^{2}}{4}+\lambda \mathrm{d}}
$$

Another expression of the diameter can be obtained using equation (7):[25].

$$
\Delta_{\mathrm{H}}=\mathrm{D}=\frac{\lambda}{2}+\frac{2 d}{\sqrt{\varepsilon_{r}+1}}
$$

Where $\lambda$ is the wavelength in $(\mathrm{m})$;

$\mathrm{d}$ is the vertical distance between the antenna and the reflector surface in $(\mathrm{m})$;

$\varepsilon_{r}$ is the relative permittivity of the medium;

Other researchers define the horizontal resolution as the distance between the half-power points of the spatial response of the scatterer at the plane of the surface: [22].

$$
\Delta_{\mathrm{H}}=4 \mathrm{~d} \sqrt{\frac{\ln 2}{2+\alpha z}}
$$

\section{RESULTS AND DISCUSSION}

\subsection{Detect targets}

In this paragraph, we will start simulating the detection of buried objects with different geometric shapes, using the 400 $\mathrm{MHz}$ antenna and the radar pulse type of Kupper. The use of two types of dielectric and conductive objects have been buried at depth $1 \mathrm{~m}$ in the Medium of soil with physical properties (Medium: $\varepsilon=9 \quad \sigma=0.001$ ). The objects used are of various geometric shapes, circular $(\mathrm{R}=0.05)$, rectangular $(\mathrm{L}=50 \mathrm{~cm}$ and $\mathrm{W}=10 \mathrm{~cm})$, and square $(\mathrm{L}=10 \mathrm{~cm})$. In Figure $4 \mathrm{a}$, the detection of buried dielectrics objects is simulated and Figure $4 \mathrm{~b}$ of the conductive targets. 


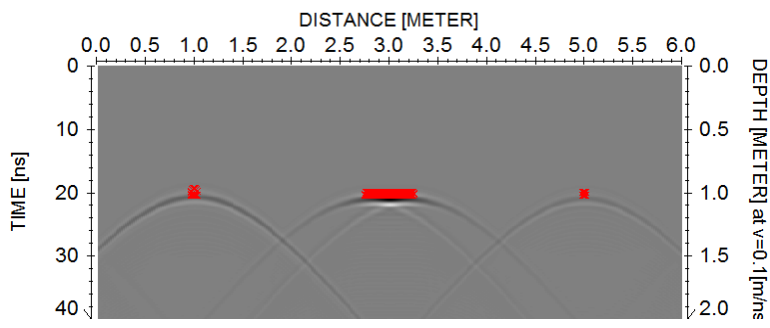

(a)

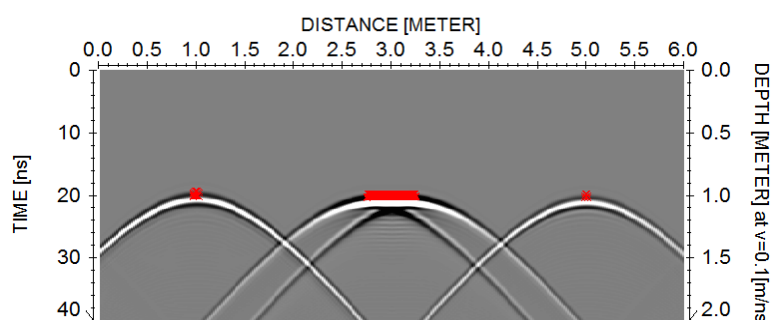

(b)

Figure 4: Radargram of detect targets buried in soil (a) dielectric and (b) conductor.

\subsection{Horizontal buried targets of same type}

In this model we simulate detection targets buried at depth $1 \mathrm{~m}$ and different horizontal distances $(20,40,75 \mathrm{~cm})$ as shown in figure 5.

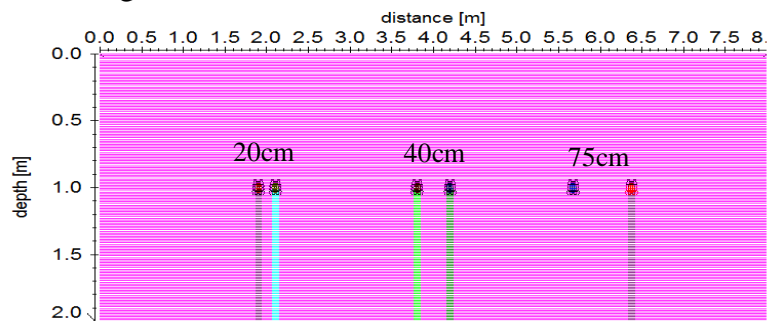

Figure 5:Modeling bar circle $(\mathrm{R}=0.04)$

The model shows the objects buried together with spacing horizontal (20; 40 and $75 \mathrm{~cm})$.

\section{A. Dielectric bars}

The simulation resolution of the GPR antenna for detection of the targets buried in the medium of soil and air, the first case soil and second air as shown in Figures $6 \mathrm{a}$ and $6 \mathrm{~b}$, the bars used are dielectric. The simulation frequencies have been set at $400 \mathrm{MHz}$. The emission and reflection of the simulated signal were recorded over the effective pulse duration of $1.3 \mathrm{~ns}$ for $400 \mathrm{MHz}$ antenna. The results obtained from the measured vertical resolutions have been summarized. They have also been presented as shown in Figure $6 a$ for the medium of soil and $6 b$ for the medium of air. In this figure we note the presence of diffraction hyperbolas which indicates the presence of the targets.

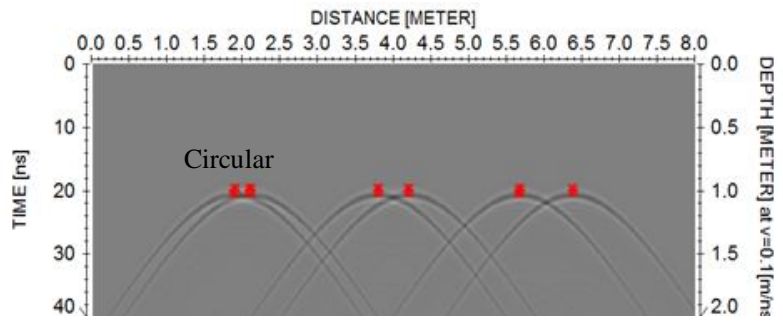

(a)



(b)

Figure 6: Radargram of the detection two dielectric bars buried horizontal with spacing $20 \mathrm{~cm}(\mathrm{x} 1=1.9, \mathrm{x} 2=1.10), 40 \mathrm{~cm}(\mathrm{x} 1=$ $3.8, \mathrm{x} 2=4.20)$ and $75 \mathrm{~cm}(\mathrm{x} 1=5.675, \mathrm{x} 2=6.375)(\mathrm{a})$ soil medium (b) air medium.

\section{B. Conductors bars}

The same thing in Figure 7, we buried two targets in a circular shape and with a conductivity (conductor) with three spacing distances.



(a)

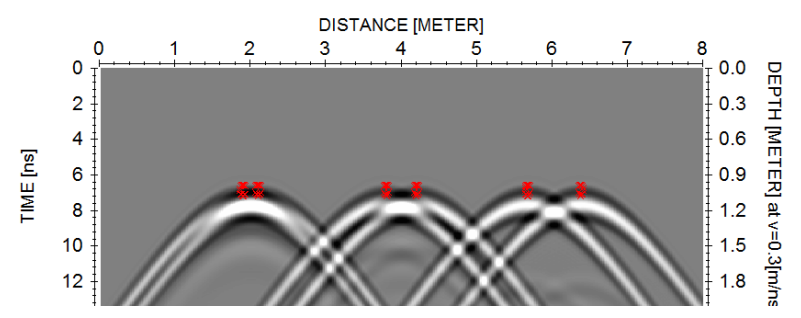

(b)

Figure7:Radargram of the detection two-conductor bars buried horizontal with spacing $20 \mathrm{~cm}, 40 \mathrm{~m}$ and $75 \mathrm{~cm}$ (a) soil medium (b) air medium.

\section{Conductor and dielectric horizontal spacing}

In this part, we use targets different in the physical characteristics as a good conductor and a good dielectric and separated by a horizontal distance, $20 \mathrm{~cm}, 40 \mathrm{~cm}$, and $75 \mathrm{~cm}$ as in figure 8 . Note in Figure 8 that the impact of high conductivity bar iron very strongly on the wooden bar, almost entirely disappeared. In figure 8 , the distance interval of $40 \mathrm{~cm}$ and still an influence by the iron rod on the wood, but less. 


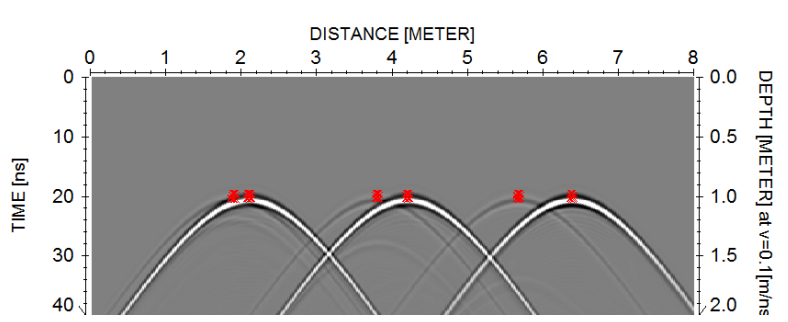

(a)



Figure 8: Radargram of the detection two bars conductor and dielectric buried together horizontal with spacing $20 \mathrm{~cm}, 40 \mathrm{~cm}$ and $75 \mathrm{~cm}$; (a) soil medium (b) air medium.

\subsection{Buried bars vertical spacing}

In figure 9 shows the modeling of detection of the targets circle (Figure 9a) and rectangular (Figure 9b) buried with spacing vertical.

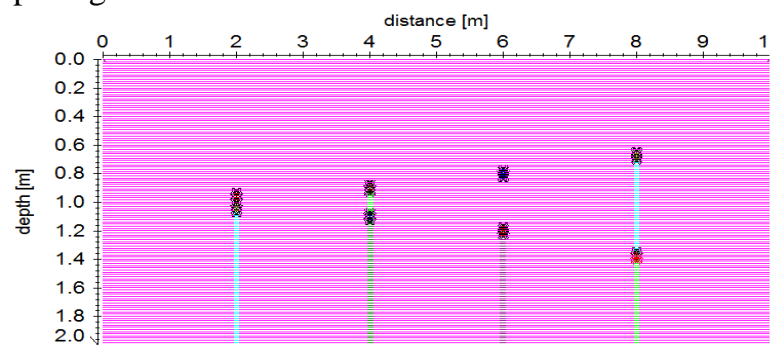

(a)

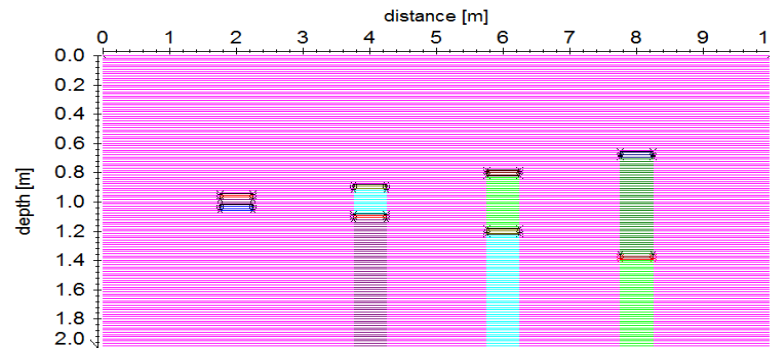

(b)

Figure 9: Modeling for detection of the targets buried vertical spacing.

(a): Two circle bars, (b): Two conductor bars

\section{A. Conductor targets buried with spacing vertical}

In this part, we utilize in the simulation two mediums dry sand the first case and air for the second case. an iron and wooden bar as form circular with $0.04 \mathrm{~cm}$ in diameter and rectangle bars $(\mathrm{w}=0.04,1=0.5)$ was buried at a depth of 1 $\mathrm{m}$ and located on the surface at four different distances $(5$, $20,40,75 \mathrm{~cm})$. The radargrams illustrated the emission and reflection of the signal were recorded over the effective pulse duration of $1.3 \mathrm{~ns}$ for $400 \mathrm{MHz}$ antenna. The results obtained from the measured vertical resolutions have been summarized in Table 2 for the theory of the $400 \mathrm{MHz}$ antenna and the simulation. They have also been presented as shown in Figure 10a, 10b. In this figure we note the presence of two diffraction hyperbolas which indicate the presence of the bars. This is exactly the depth at which the iron or bar of dielectric was supposed to be buried.
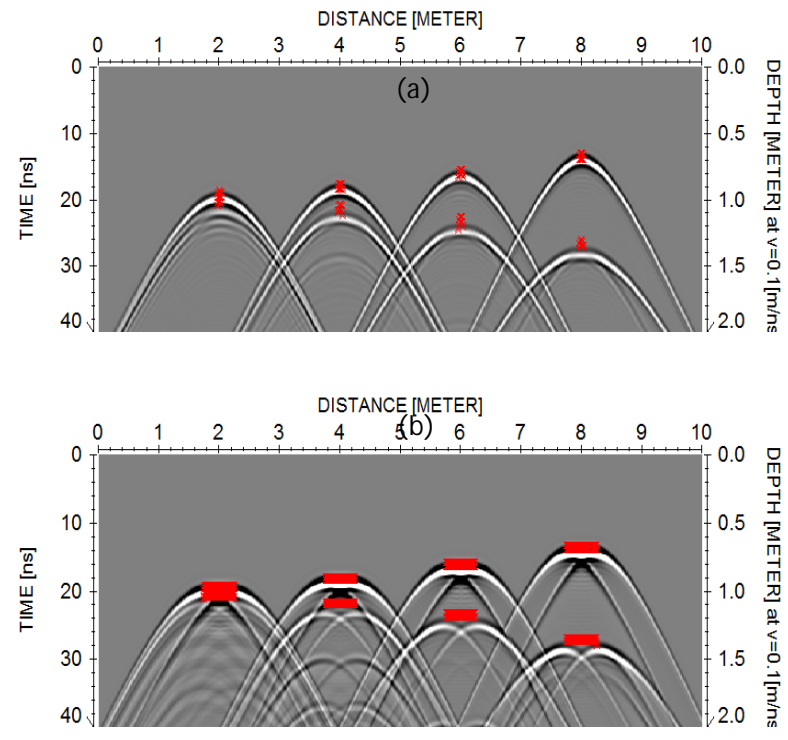

(b)

Figure 10:Radargram of the detection two bars conductor buried together vertical with spacing $5 \mathrm{~cm}, 20 \mathrm{~cm}, 40 \mathrm{~cm}$ and $75 \mathrm{~cm}$; (a) soil medium (b) air medium.

\section{B. wooden bars buried Vertical}

The same work as in the previous paragraph only here are dielectric targets and the results are shown in figure 11.

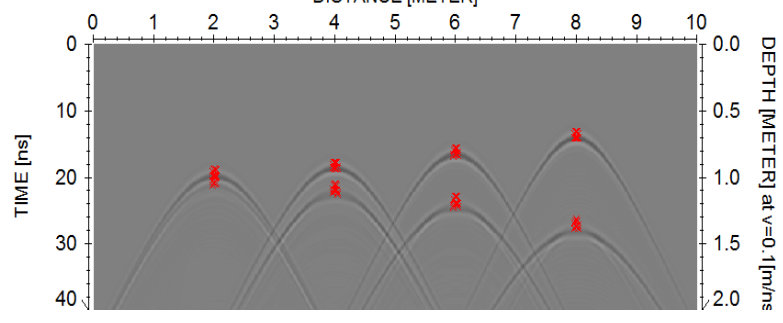

(a)

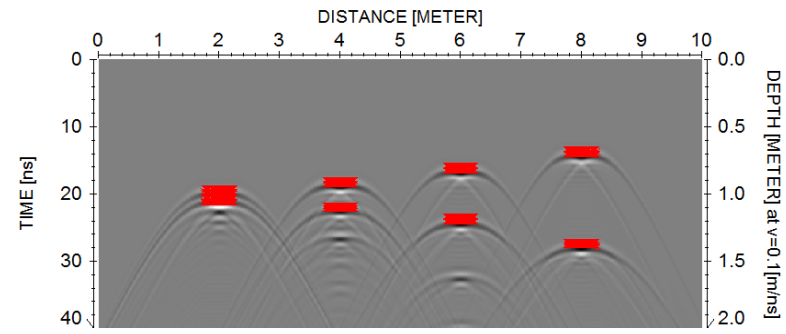

(b)

Figure 11:Radargram of the detection two bars dielectric buried together vertical with spacing $5 \mathrm{~cm}, 20 \mathrm{~cm}, 40 \mathrm{~cm}$ and $75 \mathrm{~cm}$; (a) circular (b) rectangular 


\section{Dielectric and conductor bars buried together with vertical spacing}

In this part, we will simulate the resolution of the radar GPR in detecting objects in the form of rectangular and different physical properties conductor and dielectric as shown in the figure $12 \mathrm{a}$ and $12 \mathrm{~b}$.


(b)

Figure 12: Radargram of the detection of two bars rectangular dielectric and conductive $(5,20,40,75 \mathrm{~cm})$.

\subsection{Three bars dielectric and conductor buried together}

In figure 13, we will simulate the resolution of the radar GPR in detecting three objects in the form of rectangular and different physical properties conductor and dielectric as shown in figure 13.



Figure 13:Radargram of resolution Radar GPR for detection three bars dielectric and conductor buried together with spacing vertical.

\subsection{Cavity}

At the end of this work we will simulate the detection of submerged cavities inside a conductive or dielectric medium as shown in figure 13.

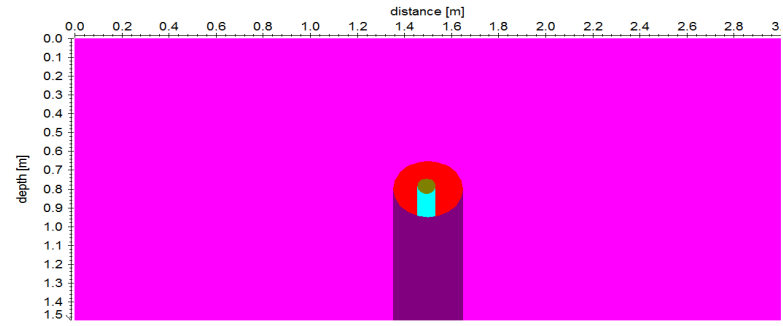

Figure 14:Modeling detection of the cavity inside the medium of dielectric or conductor.



(a)

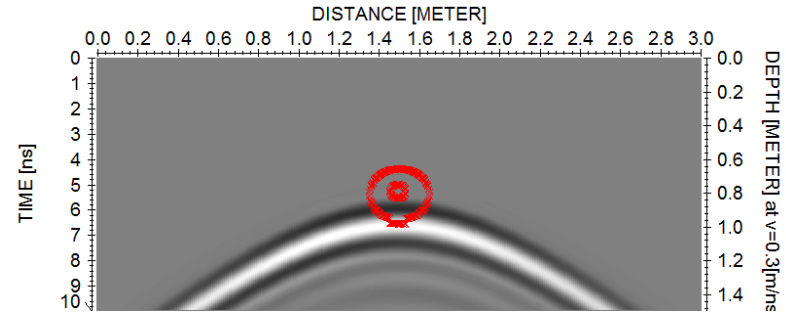

(b)

Figure 15:Radargram of the detection of the cavity with the diameter $15 \mathrm{~cm}$; (a) cavities of the conductor $(0.15)$ filled with a dielectric $(0.04 \mathrm{~cm})$; b) dielectric cavities $(0.15)$ filled with conductor (0.04).

\section{CONCLUSION}

After performing this simulation to study the resolution of the radar GPR using the Reflexw program, which depends on the FDTD method, it was effective and successful, and is considered the first of its kind. We were able to discover the different things in the physical properties, buried together, and distinguish them. In this work, the emphasis was placed on the antenna accuracy with $400 \mathrm{MHz}$, which is considered the most used. Through the previous results, we note that several factors affect the resolution of the radar GPR, including the types of the medium for example (soil or air) distances between the targets horizontal or vertical and the type of frequency.

\section{REFERENCES}

1. DANIELS, David J. Ground penetrating radar. Encyclopedia of RF and microwave engineering, 2005. https://doi.org/10.1002/0471654507.eme152

2. CONYERS, Lawrence B. Ground-penetrating radar for archaeology. Altamira Press, 2013. 
3. BENEDETTO, Andrea et PAJEWSKI, Lara (ed.). Civil engineering applications of ground-penetrating radar. Springer, 2015. https://doi.org/10.1007/978-3-319-04813-0

4. CONYERS, Lawrence B. Interpreting groundpenetrating radar for archaeology. Routledge, 2016. https://doi.org/10.4324/9781315426334

5. Giannopoulos, A.The investigation of transmissionline matrix and finite-difference time-domain methods for the forward problem of ground probing radar. Ph.D. thesis, Department of Electronics, University of York, York, UK ,1997.

6. G. Alsharahi, A. Mint Mohamed Mostapha, Modelling and Simulation Resolution of Ground Penetrating Radar Antennas, Journal of electromagnetic engineering and science ,2016.

https://doi.org/10.5515/JKIEES.2016.16.3.182

7. GIANNAKIS, Iraklis, GIANNOPOULOS, Antonios, et WARREN, Craig. A realistic FDTD numerical modeling framework of ground penetrating radar for landmine detection. IEEE Journal of selected topics in applied earth observations and remote sensing, 2015, vol. 9, no 1, p. 37-51.

8. Jaganathan, Arun P., ALLOUCHE, Erez, et SIMICEVIC, Neven. Numerical modeling and experimental evaluation of a time-domain UWB technique for soil void detection. Tunneling and underground space technology, 2010, vol. 25, no 6, p. 652-659.

https://doi.org/10.1016/j.tust.2009.08.006

9. ALSHARAHI, Gamil, MOSTAPHA, Aye Mint Mohamed, FAIZE, Ahmed, et al.Modelling and simulation resolution of ground-penetrating radar antennas. Journal of electromagnetic engineering and science, 2016, vol. 16, no 3, p. 182-190.

10. ANDRÉ, Frédéric, VAN LEEUWEN, Cornelis, SAUSSEZ, Stéphanie, et al. High-resolution imaging of a vineyard in the south of France using groundpenetrating radar, electromagnetic induction and electrical resistivity tomography. Journal of Applied Geophysics, 2012, vol. 78, p. 113-122.

https://doi.org/10.1016/j.jappgeo.2011.08.002

11. STEELMAN, Colby M., ENDRES, Anthony L., et JONES, Jon P. High-resolution ground-penetrating radar monitoring of soil moisture dynamics: Field results, interpretation, and comparison with unsaturated flow model. Water Resources Research, 2012, vol. 48, no 9.

https://doi.org/10.1029/2011WR011414

12. SANDMEIER, K. J. ReflexW version 6.0. User manual, Software Manual, Karlsruhe, Germany, 2011.

13. Alsharahi, Gamil, Driouach, Abdellah, et Faize, Ahmed. Performance of GPR influenced by electrical conductivity and dielectric constant. Procedia technology, 2016, vol. 22, p. 570-575.

14. BOSTANUDIN, Nurul. Computational methods for processing ground penetrating radar data. 2013. Thèse de doctorat. University of Portsmouth.
15. Harry M. Jol, Ground Penetrating Radar Theory and Applications, Elsevier B.v. All rights reserved 2009.

16. ALSHARAHI, Gamil, FAIZE, Ahmed, MAFTEI, Carmen, et al. Analysis and Modeling of GPR Signals to Detect Cavities: Case Studies in Morocco. Journal of Electromagnetic Engineering and Science, 2019, vol. 19, no 3, p. 177-187. https://doi.org/10.26866/jees.2019.19.3.177

17. Taflove A. Review of the formulation and applications of the finite-difference time-domain method for numerical modeling of electromagnetic wave interactions with arbitrary structures. Wave Motion; 10:547-82, 1988.

https://doi.org/10.1016/0165-2125(88)90012-1

18. Davis, J.L., Annan, A.P., 1989. Ground-penetrating radar for high-resolution mapping of soil and rock stratigraphy. Geophysical Prospecting 37, 531-551.

19. S. Trehubenko, L. Berkman, N.Yeromina, S. Petrov, Y. Bryzhatyi, H. Kovalov, V. Dachkovskyi, L. Mikhailova,The Operation of Detection Systems in Conditions of Contrast Decrease of Ground Objects, International Journal of Emerging Trends in Engineering Research, volume 8, No.1, January 2020. https://doi.org/10.30534/ijeter/2020/28812020

20. Simon Street, Nashua, New Hampshire, GSSI Antennas manual, Geophysical Survey Systems, Inc, MN30-903 Rev F,2010.

21. Yelf, R., 2004. Where is true time zero?,Proceedings of 10th International Conference on Ground Penetrating Radar, pp. 279-282.

22. Daniels, D.J., 2004. Ground Penetrating Radar, IEE Radar, Sonar and Navigation Series 15, 2nd Edition. The Institution of Electrical Engineers, London, UK https://doi.org/10.1049/PBRA015E

23. Daniels, D.J., Gunton, D.J., Scott, H.F., 1988. Introduction to subsurface radar. IEE Proceedings 135 (4), 278-320 (Pt. F). https://doi.org/10.1049/ip-f-1.1988.0038

24. Pérez-Gracia, V., 2001, Evaluación GPR para aplicaciones en arqueología $y$ en patrimoniohistórico-artístico, $\mathrm{PhD}$ Thesis. (Polithechnic University of Catalonia: Barcelona, Spain). (in spanish).

25. Conyers, L.B., Goodman, D., 1997. GroundPenetrating Radar. An Introduction for Archaeologists. Altamira Press, Walnut Creek, USA. 